\title{
A Comparison of Emergence Characteristics, Intraoperative Haemodynamics and Intraoperative Brain Relaxation between Isoflurane and Desflurane in Patients Undergoing Craniotomy for Supratentorial Lesions.
}

\author{
Jitendra S Chahar', Rakesh K Dubey', Ravi Ranjan', Subhransu S Padhy', Vaishali Agarwal ${ }^{2}$ \\ ${ }^{1}$ Senior Resident, Department of Anesthesia and Critical Care, Dr. Ram Manohar Lohia Institute of Medical Sciences, Lucknow, Uttar Pradesh, India, \\ ${ }^{2} J u n i o r$ Resident, Department of Anesthesia and Critical Care, Dr. Ram Manohar Lohia Institute of Medical Sciences, Lucknow, Uttar Pradesh, India.
}

\section{Abstract}

Background: Desflurane had increased anaesthetic armamentarium for maintenance of general anesthesia in neurosurgical cases. Few studies have compared isoflurane and desflurane for patients undergoing elective supratentorial craniotomy. Aims: The aim of this study is to compare emergence characteristics, intraoperative haemodynamic and intraoperative brain relaxation between isoflurane and desflurane in patients undergoing craniotomy for supratentorial lesions. Settings and Design: Prospective randomized and comparative study. Subjects and Methods: In this study, patients were randomly allocated in two groups. Groups I and D received Isoflurane and desflurane in MAC (0.8-1.2) during maintenance of general anesthesia after endotracheal intubation till skin closure. Emergence time, Extubation time, perioperative hypertension and intraoperative brain relaxation was compared between 2 groups across different time period. Statistical Analysis: Mean and standard deviation were calculated. Test of analysis between two groups was done by t-test and then P value was calculated. Results: Significantly lesser emergence time and extubation time in group D compared to group I ( $7.53 \pm 2.11$ vs $15.10 \pm 1.7$ and $10.87 \pm 1.961$ vs 18.20 \pm 1.92 ). Perioperative haemodynamics were among comparable between both groups. Intraoperative brain relaxation was also comparable between 2 groups with more patients in desflurane group having grade 1 relaxation. Incidence of emergence hypertension and post-operative complication were also similar with 2 groups. Conclusion: It is concluded from the study that both inhalational agents isoflurane and desflurane can be used in patients undergoing supratentorial surgeries, desflurane has added advantage of faster post-operative recovery and intraoperative brain relaxation and emergence characteristics.

Keywords: Isoflurane, desflurane, supratentorial craniotomy, emergence time, extubation time, emergence hypertension.

Corresponding Author: Dr. Rakesh k Dubey, Department of Anesthesia and Critical Care, Dr. Ram Manohar Lohia Institute of Medical Sciences, Lucknow, Uttar Pradesh, India.

Received: January 2019

Accepted: January 2019

\section{Introduction}

Neuroanesthesia practice is continuously evolving. With increasing incidence of brain tumours in last few decades, surgery rates for these lesions are also increasing. Ideal neuroanesthetic agents for these procedures must have following characteristics:- reduction of cerebral metabolism, neuroprotection, hemodynamic stability, preservation of cerebral autoregulation, only mild effect on intracranial pressure (ICP), and fast patient recovery. ${ }^{[1,2]}$

Volatile anesthetics agents are commonly used for maintaining general anesthesia in craniotomies. Isoflurane is most commonly used volatile anesthetics agent in India and considered an appropriate anesthetic for intracranial surgeries due to its better effect on cerebral physiology as well as the lowered cost compared with the other inhalational anesthetics. ${ }^{[3,4]}$
Introduction of desflurane has changed neuroanesthesia practice. With its low blood gas partition coefficient, desflurane provide rapid induction and recovery. But desflurane is often criticized in neurosurgery due to its cerebral vasodilating property. Cerebral vasodilatation and increase in intracranial pressure (ICP) by desflurane has been reported in various animal and human studies. ${ }^{[5]}$ Inspite of widespread use of isoflurane and desflurane, studies directly comparing these two drugs in supratentorial surgeries are scare. Therefore we planned to conduct this study to compare Emergence characteristics, intraoperative haemodynamic and intraoperative brain relaxation between isoflurane and desflurane in patient undergoing elective supratentorial craniotomy for space occupying lesion.

\section{Subjects and Methods}

The present study entitled "A Comparison evaluation of emergence characteristics, intraoperative haemodynamics 
and intraoperative brain relaxation between isoflurane and desflurane in patients undergoing craniotomy for supratentorial lesions" was conducted at the Department of Anesthesiology and Critical care Medicine (Dr. Ram Manohar Lohia Institute of Medical sciences), a tertiary care hospital \& research Centre for period of 1 years. Ethical committee approval was taken from the institute ethical committee (IEC- 55/15). Informed consent was obtained from each patient prior to inclusion into the study. A register was kept of all patients evaluated for inclusion and of patient who chose to withdraw from the study. The study included 60 patients with American Society of Anaesthesiologists (ASA) status I and II of either sex in the age group of 20-60 years and Glasgow coma score $>12$ undergoing supratentorial craniotomy for space occupying lesion. Patients with the following conditions were excluded from the study: Patient refusal to give consent, ASA physical status $3 \& 4$, Age $<20$ and $>60$ years either sex, Glasgow coma score $<12$, patient with heart disease, hypertension, diabetes mellitus, COPD, hepatic and renal dysfunction, patients who had surgery related complications like vascular injury, massive intraoperative bleeding or injury to vital structures necessitating elective postoperative mechanical ventilation and patients with previous cranial surgery.

The primary outcome measures were: Emergence characteristics in term of- Emergence time (defined as time elapsing from end of anaesthesia until patients were able to open their eyes), Tracheal Extubation Time (defined as time elapsing from discontinuation of inhalational anaesthetics to extubation after spontaneous ventilation), Emergence hypertension, Post-operative nausea and vomiting, shivering and awareness. Secondary outcomes were-, Intraoperative brain relaxation, Intraoperative Haemodynamic i.e. Heart rate (HR) and Mean Arterial pressure (MAP).

Using computer generated randomization list, 60 patients were randomly allocated to one of the 2 groups of 30 each.

Group I: Isoflurane + oxygen and air [50\%:50\%]

Group D: Desflurane + oxygen and air [50\%:50\%]

After taking $18 \mathrm{~g}$ intravenous access in pre-operative room, patients were shifted to operation theatre (OT). In OT multichannel physiologic parameters were then attached like Non-invasive blood pressure (NIBP), Pulse Oximetry, Electrocardiogram (ECG). Patients were premedicated with Midazolam $(.05 \mathrm{mg} / \mathrm{kg})$ i.v. and Fentanyl $(2-3 \mathrm{mcg} / \mathrm{kg})$ i.v. General anaesthesia was induced with Propofol (2-2.5 $\mathrm{mg} / \mathrm{kg}$ ) i.v. till loss of verbal response and vecuronium $(0.1 \mathrm{mg} / \mathrm{kg})$ i.v. was given to facilitate tracheal intubation. Central venous cannulation with $7 \mathrm{fr}$ CVP catheter in right internal jugular vein and arterial (radial) cannulation with $22 \mathrm{~g}$ intravenous catheter were performed following tracheal intubation. Temperature monitoring was done using nasopharyngeal probe and urine output was monitored hourly following Foley's catheterization. Mechanical ventilation was adjusted to achieve a $\mathrm{PaCO} 2$ of $30 \pm 2 \mathrm{~mm} \mathrm{Hg}$ and the inhaled anaesthetic concentration was adjusted to obtain a minimum alveolar concentration (MAC) between 0.8 and 1.2. The end-tidal concentrations of the volatile anaesthetics and the ETCO2 were monitored continuously. After achieving a steady anaesthetic state, fresh gas flow rate was maintained at $1 \mathrm{~L} / \mathrm{min}$. Intermittent boluses of vecuronium
$(0.01-0.02 \mathrm{mg} / \mathrm{kg})$ i.v. were given as and when required. Dexamethasone $8 \mathrm{mg}$ i.v and antibiotics were given as required by the surgical procedure. Before pin insertion, Skull pin sites were infiltrated with $2 \%$ lignocaine solution and fentanyl $1 \mathrm{mcg} / \mathrm{kg}$ i.v. and propofol $0.5 \mathrm{mg} / \mathrm{kg}$ i.v. were given accordingly. Starting with skin incision, mannitol (0.5 $\mathrm{g} / \mathrm{kg}$ ) i.v. was administered over a period of 20-30 minutes.

After dural opening, the attending neurosurgeon, who was blinded to the study groups, assessed the brain condition on a 3-point scale:

1. Perfectly relaxed,

2. Satisfactory relaxation,

3. Tight brain.

Intervention like change in position, further reduction of $\mathrm{PaCO} 2$, additional mannitol or furosemide was undertaken when brain condition was of grade 3 .

Heart rate (HR) and Mean arterial blood pressure (MAP) were recorded as baseline (before anaesthesia induction), immediately after intubation and subsequently at $30 \mathrm{~min}$ interval till the time of tapering the inhalational agents. Thereafter, vitals were recorded immediately after tracheal extubation and then at $15 \mathrm{~min}$ interval till $1 \mathrm{hr}$ following surgery.

MAP $>20 \%$ above baseline and or HR $>100 /$ min or $>20 \%$ above baseline was treated with increasing the inspired concentration of isoflurane and desflurane upto 1.2 MAC, followed by fentanyl $0.5-1 \mathrm{mcg} / \mathrm{kg}$ i.v bolus, propofol 0.5 $\mathrm{mg} / \mathrm{kg}$ slow intravenous (IV) bolus and then labetalol $(5 \mathrm{mg}$ increments) if required. Decrease of MAP to $<20 \%$ below the baseline value was treated by decreasing the inhaled anaesthetic agents up to the level of $0.8 \mathrm{MAC}$ and bolus of IV fluids. Failure of blood pressure response to those agents was managed with administration of mephentermine $(5 \mathrm{mg}$ Increments). Bradycardia (as defined by $\mathrm{HR}<40 / \mathrm{min}$ for $>1 \mathrm{~min})$ was managed with atropine $(0.6 \mathrm{mg}$ i.v. bolus till max of $3 \mathrm{mg}$ i.v.). Normal body temperature was maintained using a forced-air warming blanket. All patients received ondansetron $(0.1 \mathrm{mg} / \mathrm{kg})$ i.v. and paracetamol $(15 \mathrm{mg} / \mathrm{kg})$ i.v. 30 minutes before end of surgery. Isoflurane and Desflurane was tapered at the beginning of skin suturing and stopped after skin dressing. Neuromuscular blockade was reversed with neostigmine $0.05 \mathrm{mg} / \mathrm{kg}$ i.v. and glycopyrrolate $0.01 \mathrm{mg} / \mathrm{kg}$ i.v. The trachea was extubated after (a) adequate reversal of neuromuscular blockade, (b) return of spontaneous respiration, (c) maintenance of adequate oxygen saturation on the pulse oximeter and (d) when the patient followed commands. MAP $>20 \%$ above baseline during emergence were treated with injection labetalol $(5 \mathrm{mg}$ increments). All patients were shifted to ICU after tracheal extubation. Patients were observed for $1 \mathrm{~h}$ for monitoring of postoperative complications like Post-operative nausea and vomiting, emergence agitation and shivering. Emergence hypertension was also noted. All the patients were interviewed on the second postoperative day for awareness during anesthesia using the modified Brice interview. ${ }^{[6]}$

\section{Statistical Analysis}

We intended to include minimum 50 patients in our study as per study by Paul et al. ${ }^{[7]}$ to have a statistical power of 
$>80 \%$. Data obtained from the patients under study was recorded in a standard Performa. The parametric data were expressed as mean \pm standard deviation. Test for analysis among two groups was done by analysis of student $t$ test for quantitative and Chi-square test for qualitative data. A P value of $<0.05$ was considered statistically significant and a $\mathrm{P}>0.05$ was not considered statistically significant.

\section{Results}

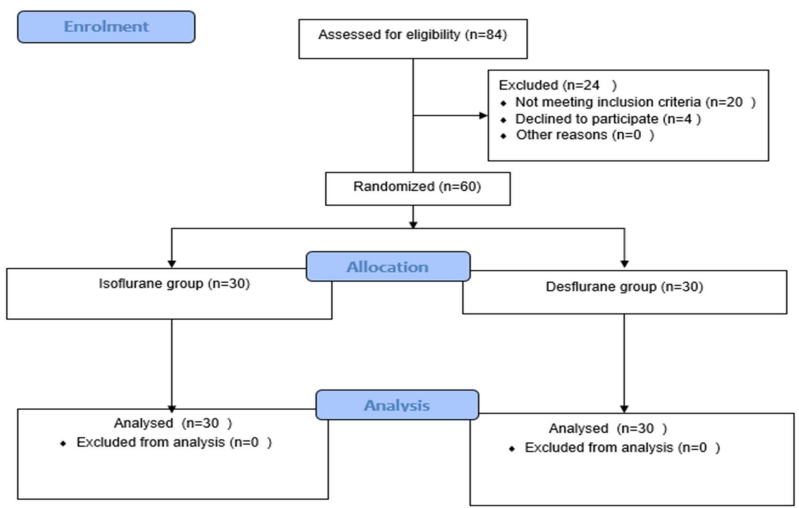

Figure 1: Consort flow diagram of study

Table 1: Demographic and intraoperative Data
\begin{tabular}{|l|l|l|l|}
\hline Parameter & $\begin{array}{l}\text { Isoflurane } \\
(\mathbf{n = 3 0})\end{array}$ & $\begin{array}{l}\text { Desflurane } \\
(\mathbf{n = 3 0})\end{array}$ & $\mathbf{P}$ \\
\hline Age (years) & $34.37 \pm 11.56$ & $35.13 \pm 10.85$ & 0.32 \\
\hline Sex (male/female) & $16 / 14$ & $17 / 13$ & 0.53 \\
\hline ASA class (I/II) & $22 / 8$ & $21 / 9$ & 0.64 \\
\hline $\begin{array}{l}\text { Tumour type } \\
\text { (astrocyte/glioma/meningioma) }\end{array}$ & $0 / 23 / 7$ & $1 / 21 / 9$ & 0.71 \\
\hline Duration of anaesthesia (h) & $3.46 \pm 1.04$ & $3.35 \pm 1.16$ & 0.46 \\
\hline Intravenous fluids infused (L) & $3.25 \pm 0.80$ & $3.22 \pm 0.73$ & 0.39 \\
\hline Estimated blood loss (L) & $0.39 \pm 0.19$ & $0.40 \pm 0.15$ & 0.82 \\
\hline Urine output (L) & $1.12 \pm 0.67$ & $1.10 \pm 0.70$ & 0.38 \\
\hline
\end{tabular}

Values expressed as mean $\pm \mathrm{SD} /$ number of patients. SD: standard deviation

Table 2: Emergence and Extubation time among 3 groups

\begin{tabular}{|l|l|l|l|}
\hline Parameter & GROUP-I & GROUP-D & p-value \\
\hline Emergence time(min) & $14.10 \pm 1.45$ & $8.53 \pm 1.79$ & 0.001 \\
\hline $\begin{array}{l}\text { Extubation time(min) } \\
\text { (Mean } \pm \text { SD) }\end{array}$ & $17.23 \pm 1.92$ & $11.57 \pm 1.961$ & 0.001 \\
\hline
\end{tabular}

Values expressed as mean $\pm \mathrm{SD} /$ number of patients. SD: standard deviation

Table 3: Intraoperative Brain relaxation grade among 3 groups

\begin{tabular}{|c|c|c|l|}
\hline Brain Grade & Group I & Group D & P Value \\
\hline 1 & 18 & 23 & 0.35 \\
\cline { 1 - 3 } & 9 & 7 & \\
\hline 3 & 3 & 0 & \\
\cline { 1 - 2 } & &
\end{tabular}

Table 4: Post-operative complication

\begin{tabular}{|l|l|l|l|}
\hline \multirow{2}{*}{ Complication } & Group & \multirow{2}{*}{ P value } \\
\cline { 2 - 3 } & $\begin{array}{l}\text { Group I } \\
\text { (Isoflurane) }\end{array}$ & $\begin{array}{l}\text { Group D } \\
\text { (Desflurane) }\end{array}$ & \\
\hline PONV & 1 & 1 & 0.35 \\
\hline Agitation & 0 & 2 & 0.22 \\
\hline Shivering & 5 & 5 & 0.83 \\
\hline Emergence HTN & 7 & 11 & 0.35 \\
\hline Convulsions & 0 & 2 & 0.33 \\
\hline Awareness & 0 & $0^{*}$ & \\
\hline
\end{tabular}

Values are mean $+\mathrm{SD} /$ numbers, *unable to assess in one patient due to motor aphasia, PONV: Postoperative nausea and vomiting,

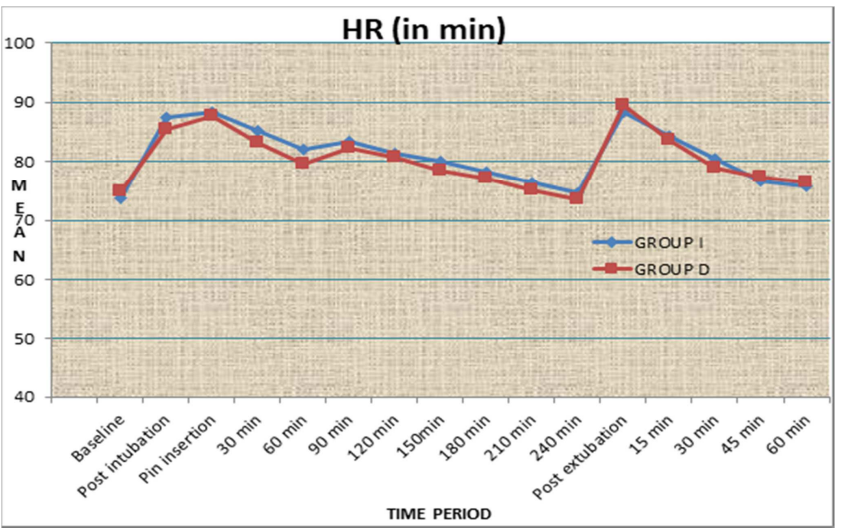

Figure 2: Heart Rate comparison between 2 groups across different time periods

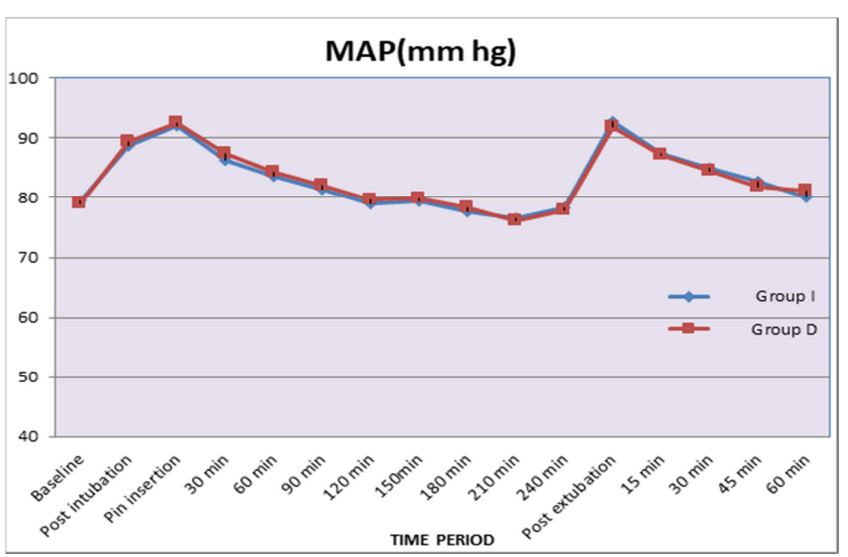

Figure 3- Mean Arterial pressure comparison between 2 groups across different time periods

Sixty patients undergoing surgery for supratentorial tumour resection between March 2017 and april 2018 were enrolled in the study. The demographic profile, total duration of anaesthesia and intraoperative data were comparable in the two groups [Table 1]. The Heart rate both intraoperative and post extubation was found to be higher in isoflurane group compared to that in desflurane group. However the differences in HR was found to be statistically insignificant among groups across all time periods with $\mathrm{p}$ value $>0.05$ [Figure 2]. After comparing MAP among the groups, $p$ values were found similar across different time periods with increase at time of intubation, pin insertion and extubation. Overall there was no significant difference found ( $p$ value $>0.005$ ) among two groups [Figure 3]. The emergence time in group I was longer than group D $(14.10 \pm 1.45 \mathrm{~min}$ vs $8.53 \pm 1.79 \mathrm{~min})$. The difference in emergence time between 2 groups was highly significant with $\mathrm{p}$ value 0.001 [Table 2]. Similarly the extubation time was shorter in Group D in comparison to group I (17.23 $\pm 1.92 \mathrm{~min}$ vs $11.57 \pm 1.96 \mathrm{~min})$. The difference in extubation time between two groups was highly significant with $\mathrm{p}$ value 0.001 [Table 2]. As judged by operating Neurosurgeon intraoperative brain relaxation was comparable among 2 groups. 23 patients in the desflurane group has grade 1 brain swelling comparing to 18 patients in isoflurane group. However with $\mathrm{p}$ value 0.35 insignificant difference was found among groups in brain relaxation grading [Table 3]. The incidence of postoperative complications was comparable among the two groups [Table 
4]. 11 patients in desflurane had emergence hypertension comparable to78 patients in isoflurane groups. 2 patients were agitated in desflurane group on emergence. Incidence of PONV and shivering also similar in both groups. None of the patients in the two groups had any incidence of awareness under anaesthesia [Table 4].

\section{Discussion}

Desflurane has a lower blood gas solubility (partition coefficient of 0.42) compared to isoflurane (partition coefficient of 1.4). This difference in the partition coefficient is responsible for the early emergence from anesthesia associated with desflurane. Our study demonstrates that desflurane, compared to isoflurane, significantly reduces the emergence times as well as extubation times in patients undergoing an elective craniotomy for supratentorial tumours with our anesthetic protocol. The previous studies have compared desflurane and isoflurane with regard to emergence and extubation times in a variety of non $\square$ neurosurgical procedures. ${ }^{[8-12]}$ Kaye et al. ${ }^{[13]}$ in there study on effect of desflurane and isoflurane on the lumbar cerebrospinal fluid (CSF) pressures in patients with intracranial tumours, also recorded emergence times after supratentorial craniotomies. Although the authors found that patients who received desflurane $(n=18)$ were able to open their eyes and obey commands in $50 \%$ less time than those who received isoflurane $(n=18)$, the differences were not significant. Boisson $\square$ Bertrand et al. ${ }^{[14]}$ found that, after long duration acoustic neuroma surgery, the emergence time in the Desflurane group was significantly faster than the I group (D: $14.9+/-2.4 \mathrm{~min}$ vs I: $29.2+/-2.4 \mathrm{~min}$ for eye-opening, $\mathrm{p}<0.01)$. Wolf et al. ${ }^{[15]}$ studied 20 infants undergoing general anaesthesia for pyloromyotomy with either desflurane or isoflurane and reached to similar results; they observed that approximately twice the speed of recovery was elicited with desflurane anaesthesia when compared with isoflurane. Agoliati et al. ${ }^{[16]}$ reported from there meta-analysis that desflurane reduced the mean extubation time by $34 \%$ over isoflurane in a variety of surgeries. In our study, we also found median emergence time and extubation time with desflurane $8 \mathrm{~min}$ earlier than that with isoflurane, thus facilitating an early postoperative neurological examination. Moreover, isoflurane anesthesia was associated with a higher incidence of delayed awakening. Maintenance of stable haemodynamic is an important part of the neuroanesthesia practice. Our patients had similar haemodynamic profile with the use of both agents at most of the observations during the study period. Ghoneim et al. ${ }^{[17]}$ found comparable HR in there comparison of isoflurane, sevoflurane and desflurane in paediatrics patients undergoing supratentorial surgeries. Yildiz et al. ${ }^{[18]}$ reported no significant difference in HR in there study comparing 1 MAC Desflurane with 1 MAC Isoflurane in 70 patients undergoing Craniotomy for Supratentorial Lesions. No significant tachycardia or hypertension could be detected during the administration of the inhalational anaesthetics in our study. These findings are due to the relative stability of the end-tidal anaesthetic concentration throughout the surgery and the simultaneous repetition of both fentanyl and muscle relaxant throughout the anaesthesia. Cahalan et al. ${ }^{[19]}$ in there study on 81 patients undergoing elective surgery studied response on HR to enflurane, halothane, and isoflurane and the effects of narcotics on this response and concluded that prior administration of morphine or concurrent administration of fentanyl may significantly decrease HR when used with inhalational anaesthetics in clinical settings. As increased brain retraction pressure is related to the occurrence of regional cerebral dysfunction, ${ }^{[20]}$ we wanted good brain relaxation during surgery. In our study we found comparable brain relaxation among 2 groups with most patients having grade I. our finding is consistent with the findings of Todd et al. ${ }^{[21]}$ who described a $10 \%$ incidence of brain swelling in patients undergoing neurosurgical resection of tumours while receiving isoflurane and $\mathrm{N} 2 \mathrm{O}$ anaesthesia. Turner et al. ${ }^{[22]}$ found in his study that there is a low association between the degree of brain swelling and lumbar cerebrospinal fluid pressure so long the intracranial pressure maintained within the normal range for pressure values. In our study we relied on clinical evaluation by a blinded neurosurgeon to assess the influence of the two anaesthetics on brain relaxation during surgical operation in the usual clinical scenario. Early emergence is usually associated with hypertension which may predispose to formation of intracranial hematoma. ${ }^{[23]}$ The occurrence of hypertension during emergence has been reported to be more than $90 \%$ in neurosurgical patients. In our study 11 patients in desflurane had emergence hypertension in comparison to 7 patients in isoflurane groups with $p$ value- 0.350 no significant differences were seen among groups. The incidence of PONV was also found to be comparable. The results of our study are similar to previously published studies, which did not demonstrate any significant difference in the incidence of early postoperative complication with use of different anaesthetic agents. ${ }^{[24]}$ Wallenborn $\mathrm{J}$ et al, ${ }^{[25]}$ in there study, the impact of isoflurane, desflurane, or sevoflurane on the frequency and severity of postoperative nausea and Vomiting after lumbar disc surgery and found that type of inhalation anaesthetic had no influence on PONV frequency.

The present study has limitations of its own. Instead of neurosurgeon satisfaction monitoring of intracranial pressure would have been ideal. With current trend of reducing anesthesia $\square$ related costs, the costs of desflurane need to be considered before using it widely for neuroanesthesia. Our sample size was probably not adequate enough to clearly establish supremacy of desflurane over isoflurane for supratentorial craniotomy.

The present study is a preliminary trial. The results of the present study need to be corroborated by conducting a large multicentre randomised clinical trial.

\section{Conclusion}

In this study, it can be concluded that although both isoflurane and desflurane can be used in patients undergoing supratentorial surgeries, desflurane has added advantage of faster post-operative recovery and intraoperative brain relaxation and emergence characteristics. 
1. Schifilliti D, Grasso G, Conti A, Fodale V. Anaesthetic-related neuroprotection: intravenous or inhalational agents? CNS Drugs 2010; 24:893-937

2. Bruder N, Ravussin PA. Supratentorial masses: Anaesthetic considerations. In: Cottrell JE, Young WL, editors. Cottrell and Young's Neuroanaesthesia. 5th ed. Philadephia: Elsevier; 2010. p. $184 \square 202$.

3. Stoelting RK, Hillier SC, editors. Inhaled anaesthetics. In: Pharmacology and Physiology in Anaesthetic Practice. 4th ed. Philadelphia: Lippincott Williams and Wilkins; 2006.p. $42 \square 86$.

4. Newberg LA, Milde J. The cerebral metabolic effects of isoflurane at and above concentrations that suppress cortical electrical activity. Anesthesiology 1983;59:23-8

5. Muzzi DA, Losasso TJ, Dietz NM, Faust RJ, Cucchiara RF, Milde LN The effect of desflurane and isoflurane on cerebrospinal fluid pressure in humans with supratentorial mass lesions. Anesthesiology 1992;76:720-4.

6. Bruder N.J. Awakening management after neurosurgery for intracranial tumours. Curr Opin Anesthesiol 2002;15:477- 82.

7. Paul AP, Vedantam A, Korula G, Chacko AG. A comparison of the recovery profiles of desflurane and isoflurane anesthesia in patients undergoing elective supratentorial craniotomy: A randomized controlled trial. Neurol India 2017;65:1053-8.

8. Juvin P, Servin F, Giraud O, Desmonts JM. Emergence of elderly patients from prolonged desflurane, isoflurane, or propofol anesthesia Anesth Analg 1997;85:647 $\square 51$.

9. Behne M, Wilke HJ, Lischke V. Recovery and pharmacokinetic parameters of desflurane, sevoflurane, and isoflurane in patients undergoing urologic procedures. J Clin Anesth 1999;11:460 $\square 5$.

10. Juvin P, Vadam C, Malek L, Dupont H, Marmuse JP, Desmonts JM. Postoperative recovery after desflurane, propofol, or isoflurane anesthesia among morbidly obese patients: A prospective, randomized study. Anesth Analg 2000;91:714 $\square 9$.

11. Beaussier M, Deriaz H, Abdelahim Z, Aissa F, Lienhart A. Comparative effects of desflurane and isoflurane on recovery after long lasting anaesthesia. Can J Anaesth 1998;45:429 $\square 34$.

12. Singh R, Kharbanda M, Sood N, Mahajan V, Chatterji C. Comparative evaluation of incidence of emergence agitation and post $\square$ operative recovery profile in paediatric patients after isoflurane, sevoflurane and desflurane anaesthesia. Indian J Anaesth 2012;56:156 $\square 61$.

13. Kaye A, Kucera IJ, Heavner J, Gelb A, Anwar M, Duban M, et al. The comparative effects of desflurane and isoflurane on lumbar cerebrospinal fluid pressure in patients undergoing craniotomy for supratentorial tumors. Anesth Analg 2004;98:1127 $\square 32$.
14. Boisson $\square$ Bertrand D, Laxenaire MC, Mertes PM. Recovery after prolonged anaesthesia for acoustic neuroma surgery: Desflurane versus isoflurane. Anaesth Intensive Care 2006;34:338 $\square 42$.

15. Wolf A, Lawson A, Dryden M, Davies F.W. Recovery after desflurane anaesthesia in the infant: Comparison with isoflurane. Br. J. Anaesth 1996;76: 362-404

16. Agoliati A, Dexter F, Lok J, Masursky D, Sarwar MF, Stuart SB, Bayman EO, Epstein RH. Meta $\square$ analysis of average and variability of time to extubation comparing isoflurane with desflurane or isoflurane with sevoflurane. Anesth Analg 2010;110:1433 $\square 9$.

17. Ghoneim, Ayman A. Awakening properties of Isoflurane, sevoflurane and desflurane in paediatric patients after craniotomy for supratentorial tumours. J Neurosurgical Anesthesiol 2009; 27:1-6.

18. Karamehmet Y, Cihangir B, Recep A, Kudret D. A Comparison of 1 Minimum Alveolar Concentration Desflurane and 1 Minimum Alveolar Concentration Isoflurane Anesthesia in Patients Undergoing Craniotomy for Supratentorial Lesions. Curr Ther Res Clin Exp 2011; 72: 49-59.

19. Cahalan M.K., Lurz F.W., Eger E.I., ShwartzL.A., Smith J.J. Narcotics decrease heart rate during inhalational anesthesia. Anesth Analg 1989; 66:166-70.

20. Gauthier A, Girard F, Boudreault D, Ruel M, Todorov A. Sevoflurane provides faster recovery and postoperative neurological assessment than isoflurane in long-duration neurosurgical cases. Anesth Analg 2002;95:1384-1408.

21. Todd MM, Warner DS, Sokoll MD, Maktabi MA, Hindman BJ, Scamman FL, et al. A prospective, comparative trial of three anesthetics for elective supratentorial craniotomy. Propofol/ fentanyl, isoflurane/nitrous oxide, and fentanyl/nitrous oxide. Anesthesiology 1993;78:1005-20.

22. Turner CR, Lossaco TJ, Muzzi DA. Brain relaxation and cerebral fluid pressure during craniotomy for resection of supratentorial mass lesions. J Neurosurg Anesthesiol 1996;8:126-32.

23. Basali A, Mascha EJ, Kalfas I, Schubert A. Relation between perioperative hypertension and intracranial hemorrhage after craniotomy. Anesthesiology 2000;93:48-54.

24. Rosa G, Pinto G, Orsi P, de Blasi RA, Conti G, Sanita R, et al . Control of post anaesthetic shivering with nefopam hydrochloride in mildly hypothermic patients after neurosurgery. Acta Anaesthesio Scand 1995;39:90-5.

25. Wallenborn J, Rudolph C, Gelbrich G, Goerlich TM, Helm J, Olthoff D. The impact of isoflurane, desflurane, or sevoflurane on the frequency and severity of postoperative nausea and vomiting after lumbar disc surgery. J Clin Anesth. 2007;19:180-205.

Copyright: ( ) the author(s), publisher. Academia Anesthesiologica International is an Official Publication of "Society for Health Care \& Research Development". It is an open-access article distributed under the terms of the Creative Commons Attribution Non-Commercial License, which permits unrestricted non-commercial use, distribution, and reproduction in any medium, provided the original work is properly cited.

How to cite this article: Chahar JS, Dubey RK, Ranjan R, Padhy SS, Agarwal V. A Comparison of Emergence Characteristics, Intraoperative Haemodynamics and Intraoperative Brain Relaxation between Isoflurane and Desflurane in Patients Undergoing Craniotomy for Supratentorial Lesions. Acad. Anesthesiol. Int. 2018;3(2):22-26.

DOI: dx.doi.org/10.21276/aan.2018.3.2.5

Source of Support: Nil, Conflict of Interest: None declared. 